Research Paper

\title{
Refining the American Joint Committee on Cancer Staging Scheme For Resectable Pancreatic Ductal Adenocarcinoma Using Recursive Partitioning Analysis
}

\author{
Yiquan Jiang1*, Yanhong $\mathrm{Su}^{2 *}$, Yutong Chen ${ }^{2 *}$, Zhiyong $\mathrm{Li}^{3 凶}$ \\ 1. Department of Hepatobiliary and Pancreatic Surgery, Sun Yat-sen University Cancer Center, State Key Laboratory of Oncology in South China, \\ Collaborative Innovation Center for Cancer Medicine, Guangzhou 510060, China; \\ 2. Department of Medical Oncology, Sun Yat-sen University Cancer Center, State Key Laboratory of Oncology in South China, Collaborative Innovation \\ Center for Cancer Medicine, Guangzhou 510060, China; \\ 3. Department of Urology, Sun Yat-sen University Cancer Center, State Key Laboratory of Oncology in South China, Collaborative Innovation Center for \\ Cancer Medicine, Guangzhou 510060, China. \\ * These authors contributed equally as first authors. \\ $\square$ Corresponding author: Zhiyong Li, 651 Dong Feng Road East, Guangzhou 510060, China; Tel and Fax: +86-20-8734 3088; E-mail: lizhiy@sysucc.org.cn. \\ (c) Ivyspring International Publisher. This is an open access article distributed under the terms of the Creative Commons Attribution (CC BY-NC) license \\ (https://creativecommons.org/licenses/by-nc/4.0/). See http://ivyspring.com/terms for full terms and conditions.
}

Received: 2017.02.06; Accepted: 2017.05.19; Published: 2017.08.23

\begin{abstract}
Purpose: It remains unclear whether the recently proposed $8^{\text {th }}$ edition of the American Joint Committee on Cancer (AJCC) staging scheme for pancreatic ductal adenocarcinoma (PDAC) outperforms the $7^{\text {th }}$ edition. We assessed the prognostic performance of both these schemes and performed recursive partitioning analysis (RPA) to objectively regroup the $7^{\text {th }}$ and $8^{\text {th }}$ AJCC stages and derive a refined staging scheme.

Methods: We examined 8542 patients with resectable PDAC from the 2004-2012 Surveillance, Epidemiology, and End Results database. The dataset was randomly divided into training and validation sets. The performance of different staging schemes was evaluated in terms of prognostic stratification, discriminatory ability, and prognostic homogeneity.

Results: The $7^{\text {th }}$ and $8^{\text {th }} \mathrm{T}$ classifications showed prominent heterogeneity within each subcategory when assessed against each other in the case of node-negative disease. RPA divided resectable PDAC into RPA-IA ( $8^{\text {th }}$ T1N0 limited to the pancreas), RPA-IB ( $8^{\text {th }}$ TIN0 extending beyond the pancreas, or $8^{\text {th }}$ T2-T3N0 limited to the pancreas), RPA-IIA ( $8^{\text {th }}$ T2N0 extending beyond the pancreas, or $8^{\text {th }}$ T1N1-N2), RPA-IIB ( $8^{\text {th }}$ T3N0 extending beyond the pancreas, or $8^{\text {th }}$ T2-T3N1), and RPA-III stages ( $8^{\text {th }}$ T2-T3N2) (median survival in the training set: $47,28,20,16$, and 14 months, respectively; $P<0.001$ ). The RPA staging scheme outperformed the $7^{\text {th }}$ and $8^{\text {th }} \mathrm{AJCC}$ classifications in terms of prognostic stratification, discriminatory ability, and prognostic homogeneity for both the training and validation sets.

Conclusions: The proposed RPA staging is a superior risk-stratified tool to the $7^{\text {th }}$ and $8^{\text {th }}$ AJCC classifications and is not substantially more complex.

Key words: pancreatic ductal adenocarcinoma (PDAC); American Joint Committee on Cancer staging (AJCC); Surveillance, Epidemiology, and End Results (SEER); staging; survival.
\end{abstract}

\section{Introduction}

Pancreatic ductal adenocarcinoma (PDAC) is the fifteenth most common malignancy and is the seventh most common cause of cancer-related deaths worldwide [1]. Radical resection is the only curative option, but patients with resectable PDAC have a high risk of postsurgical recurrence and a poor overall prognosis [2].

In the $7^{\text {th }}$ edition of the American Joint
Committee on Cancer (AJCC) staging scheme [3], extrapancreatic extension is considered a more important prognostic factor than tumor size because resectable PDAC with extrapancreatic extension is categorized as T3 regardless of tumor size. Additionally, patients with nodal metastasis are assigned to a single prognostic group-the N1 classification-regardless of the positive lymph node 
count [3].

Several studies have questioned the clinical relevance and reproducibility of the $7^{\text {th }}$ AJCC staging for patients with PDAC, especially the $7^{\text {th }} \mathrm{T} 3$ classification which requires the identification of extrapancreatic extension [4]. In the recently proposed $8^{\text {th }}$ AJCC staging scheme [5], the definitions of $\mathrm{T}$ classifications for resectable PDAC were solely based on tumor size (T1, T2, and T3: $\leq 2 \mathrm{~cm},>2 \mathrm{~cm}$ and $\leq 4$ $\mathrm{cm}$, and $>4 \mathrm{~cm}$, respectively), while the $7^{\text {th }}$ AJCC N1 classification was further stratified according to the positive lymph node count (N1: 1-3 positive nodes; N2: $\geq 4$ positive nodes). However, in a recent US multi-institutional study, even though the reproducibility of the $8^{\text {th }}$ AJCC T classification system was found to be superior to that of the $7^{\text {th }}$ AJCC T classification system, the discriminatory power of the $7^{\text {th }}$ and $8^{\text {th }}$ AJCC schemes were still comparable[5].

In the present study, we first assessed the prognostic performance of the $7^{\text {th }}$ and $8^{\text {th }}$ AJCC classifications using a large population-based cohort of patients with resectable PDAC. Thereafter, we developed a refined staging scheme through objective regrouping of the $7^{\text {th }}$ and $8^{\text {th }} T$ classifications and the $8^{\text {th }} \mathrm{N}$ classifications by using recursive partitioning analysis (RPA).

\section{Methods}

\section{Study cohort}

Using the National Cancer Institute's Surveillance, Epidemiology, and End Results (SEER) database (18 registries), we included 17379 patients with PDAC (NAACCR Item \#400 [primary tumor site], codes: C25.0-C25.4; NAACCR Item \#552 [histologic type], codes: 8140, 8150, 8210, 8211, 8251, $8260,8261,8263,8480,8481,8490,8500$, and 8503) from January 2004 to December 2012. Exclusion criteria are as following: concurrent or with a history of prior malignancy, locally unresectable tumor (T4 classification), distant metastasis, tumor in situ, and missing information regarding tumor size, $6^{\text {th }}$ AJCC $\mathrm{T}$ and $\mathrm{M}$ classifications, and the number of positive nodes. The final study cohort comprised 8542 patients. PDAC in all cases was restaged on the basis of the $7^{\text {th }}$ and $8^{\text {th }}$ AJCC staging schemes.

\section{Statistical analysis}

Overall survival (OS) was the primary outcome of interest. Stratified survival analyses with the Kaplan-Meier method and log-rank tests were used to evaluate the prognostic impact of the $7^{\text {th }} T$ classification within each of the $8^{\text {th }} \mathrm{T}$ classifications and the prognostic impact of the $8^{\text {th }} \mathrm{T}$ classification within each of the $7^{\text {th }} \mathrm{T}$ classifications. Multivariate Cox regression was used to examine the association between the $7^{\text {th }}$ and $8^{\text {th }} \mathrm{T}$ classifications and hazard ratios (HRs) for death after adjustment for the clinicopathologic factors. Additionally, the capacity of the $7^{\text {th }}$ and $8^{\text {th }} \mathrm{T}$ classification systems to distinguish patients at low and high risk of death was quantified using the concordance index (C-index) [6]. The value of the C-index ranges from 0.5 to 1.0 , with 0.5 indicating a random chance and 1.0 indicating a perfect ability to correctly determine the outcome. Thus, the higher the C-index, the greater is the discriminatory capacity of the scheme.

Two-thirds of the patients in the study cohort were randomly assigned to a training set $(n=5710)$ and the remaining one-third were assigned to a validation set $(n=2832)$ to develop and validate a refined staging system which combined the prognostic information of the $7^{\text {th }}$ and $8^{\text {th }} \mathrm{T}$ classifications together with the $8^{\text {th }} \mathrm{N}$ classifications using RPA. RPA can divide patients at each step into two groups based on the covariate that provided maximum separation with respect to prognosis and accounted for interactions between factors [7, 8].

In both the training and validation sets, the performance of the RPA staging scheme was compared with the $7^{\text {th }}$ and $8^{\text {th }}$ AJCC staging schemes in terms of prognostic stratification, discriminatory ability, and prognostic homogeneity. Prognostic stratification was assessed using stratified survival analyses, which evaluated the prognostic effect of a staging scheme within each substage of the other staging scheme. The discriminatory abilities of the three staging schemes were quantified using the C-index and Akaike's information criterion (AIC) [9]. The higher the C-index or the lower the AIC value, the greater was the discriminatory ability of the staging scheme. The likelihood ratio $\chi^{2}$ test was used to measure the prognostic homogeneity of the staging schemes [10]. The higher the likelihood ratio $\chi^{2}$ value, the greater was the prognostic homogeneity of the staging scheme.

Statistical significance was set at $P<0.05$ in a two-tailed test. Statistical analyses were performed using SAS v. 9.3 (SAS Institute, Cary, NC, USA), IBM SPSS Statistics for Windows v. 19.0 (IBM Corp., Armonk, NY, USA), and R v. 3.3.1 (http://www.r-project.org). The authenticity of this article has been validated by uploading the key raw data onto the Research Data Deposit public platform (www.researchdata.org.cn), with the approval RDD number as RDDA2017000221.

\section{Results}

Table 1 summarizes the characteristics of the study cohort (8542 cases). Most patients were diagnosed as having tumor extending beyond the 
pancreas $(79.3 \%)$ and tumor with the greatest dimension $>2 \mathrm{~cm}$ and $\leq 4 \mathrm{~cm}(59.3 \%)$. Most patients had lymph node metastasis $(64.3 \%)$, and the median positive and examined lymph node counts were 1 (interquartile range [IQR]: 0-3) and 13 (IQR: 7-19), respectively. The median survival period was 18 months.

Table 1. Clinicopathologic characteristics of the study cohort of patients with resectable PDAC ( $\mathrm{N}=8542)$

\begin{tabular}{|c|c|}
\hline Variable & Median (IQR)/N (\%) \\
\hline Age, years & $66(58,74)$ \\
\hline \multicolumn{2}{|l|}{ Race } \\
\hline White & 7014 (82.1\%) \\
\hline Black & $896(10.5 \%)$ \\
\hline Other/unknown & $632(7.4)$ \\
\hline \multicolumn{2}{|l|}{ Sex } \\
\hline Male & $4332(50.7 \%)$ \\
\hline Female & $4210(49.3 \%)$ \\
\hline \multicolumn{2}{|l|}{ Marital status } \\
\hline Married & $5318(62.3 \%)$ \\
\hline Unmarried & $2992(35.0 \%)$ \\
\hline Unknown & $232(2.7 \%)$ \\
\hline \multicolumn{2}{|l|}{ Year of diagnosis } \\
\hline 2004-2006 & $2437(28.5 \%)$ \\
\hline 2007-2009 & $2966(34.7 \%)$ \\
\hline 2010-2012 & $3139(36.7 \%)$ \\
\hline \multicolumn{2}{|l|}{ SEER region } \\
\hline Midwest & $1352(15.8 \%)$ \\
\hline Northeast & $1611(18.9 \%)$ \\
\hline South & $1486(17.4 \%)$ \\
\hline West & $4093(47.9 \%)$ \\
\hline \multicolumn{2}{|l|}{ Tumor site } \\
\hline Head & $6641(77.7 \%)$ \\
\hline Body & $481(5.6 \%)$ \\
\hline Tail & $648(7.6 \%)$ \\
\hline Overlapping/unknown & $772(9.0 \%)$ \\
\hline \multicolumn{2}{|l|}{ Tumor grade } \\
\hline $\mathrm{I} / \mathrm{II}$ & $4863(56.9)$ \\
\hline III/IV & $2856(33.5)$ \\
\hline Unknown & $823(9.6 \%)$ \\
\hline Tumor size & $31(25,40)$ \\
\hline$\leq 2 \mathrm{~cm}\left(8^{\text {th }} \mathrm{T} 1\right)$ & $1466(17.2 \%)$ \\
\hline$>2 \mathrm{~cm}$ and $\leq 4 \mathrm{~cm}\left(8^{\text {th }} \mathrm{T} 2\right)$ & $5063(59.3 \%)$ \\
\hline$>4 \mathrm{~cm}\left(8^{\text {th }} \mathrm{T} 3\right)$ & $2013(23.6 \%)$ \\
\hline \multicolumn{2}{|l|}{ 7th AJCC T stage } \\
\hline $\mathrm{T} 1$ ( $\leq 2 \mathrm{~cm}$ and limited to the pancreas) & $550(6.4 \%)$ \\
\hline $\mathrm{T} 2(>2 \mathrm{~cm}$ and $\leq 4 \mathrm{~cm}$ and limited to the pancreas) & $1216(14.2 \%)$ \\
\hline T3 (extended beyond the pancreas) & $6776(79.3 \%)$ \\
\hline Positive node count & $1(0,3)$ \\
\hline $0\left(8^{\text {th }} \mathrm{N} 0\right)$ & $3049(35.7 \%)$ \\
\hline $1-3\left(8^{\text {th }} \mathrm{N} 1\right)$ & $2869(33.6 \%)$ \\
\hline$\geq 4\left(8^{\text {th }} \mathrm{N} 2\right)$ & $2624(30.7 \%)$ \\
\hline Examined node count & $13(7,19)$ \\
\hline
\end{tabular}

PDAC, pancreatic ductal adenocarcinoma; IQR, interquartile range; SEER, Surveillance, Epidemiology, and End Results; AJCC, American Joint Committee on Cancer.

Survival by $\mathrm{T}$ classification of the $7^{\text {th }}$ and $8^{\text {th }}$ AJCC schemes is presented in Figure $\mathbf{1 A}$ and 1B, respectively. In both systems, each $\mathrm{T}$ classification represented a distinct prognosis. After adjustment for race, year of diagnosis, age, sex, marital status, SEER region tumor site, tumor grade, and examined node count, higher $7^{\text {th }}$ and $8^{\text {th }} \mathrm{T}$ classifications were associated with an increased risk of death $\left(7^{\text {th }}\right.$ edition: T2 vs. T1: HR, 1.49; $P<0.001$; T3 vs. T1: HR, 1.79; $P$ $<0.001 ; 8^{\text {th }}$ edition: T2 vs. T1: HR, 1.37; $P<0.001$; T3 vs. T1: HR, 1.61; $P<0.001)$. Significant heterogeneity in median survival was identified in patients within the $7^{\text {th }} \mathrm{T} 3$ classification when stratified by the $8^{\text {th }} \mathrm{T}$ classification, and among patients within each of the $8^{\text {th }} \mathrm{T}$ classifications when stratified by the $7^{\text {th }} \mathrm{T}$ classification (Table 2). For patients with $7^{\text {th }} \mathrm{T} 3 \mathrm{~N} 0$ disease, the OS differed significantly between the $8^{\text {th }}$ T1, T2, and T3 classifications (median survival: 26, 20, and 16 months, respectively; $P<0.001$ ); within each $8^{\text {th }}$ $\mathrm{T}$ classification, the OS was significantly different between patients with and without tumor extending beyond the pancreas $(P<0.01, P<0.001$, and $P<0.01$ in the $8^{\text {th }} \mathrm{T} 1, \mathrm{~T} 2$, and T3 classifications, respectively). Of note, within the $8^{\text {th }}$ T1N0 classification, a 21-month difference in median survival was found between patients with $7^{\text {th }} \mathrm{T} 1$ and $\mathrm{T} 3$ disease (Table 2). Moreover, the $7^{\text {th }}$ and $8^{\text {th }} \mathrm{T}$ classification systems exhibited similar discriminatory capacity among patients with node-negative disease (C-indices: 0.558 vs. $0.556, P=0.42$ ).

We further assessed the consistency of predicted OS among patients with node-negative tumor extending beyond the pancreas across different SEER regions. We found that survival was homogeneous when stratified by SEER region in these patients $(P$ $=0.14$; Figure 1C).

Patient and tumor characteristics were comparable among the training set and the validation set (Table 3). The RPA algorithm classified the patients in the training set into the following five groups (Figure 2): RPA-IA (8 ${ }^{\text {th }}$ T1N0 limited to the pancreas), RPA-IB ( $8^{\text {th }}$ T1N0 extending beyond the pancreas or $8^{\text {th }} \mathrm{T} 2-\mathrm{T} 3 \mathrm{~N} 0$ limited to the pancreas), RPA-IIA (8 ${ }^{\text {th }}$ T2N0 extending beyond the pancreas or $8^{\text {th }}$ T1N1-N2), RPA-IIB ( $8^{\text {th }}$ T3N0 extending beyond the pancreas or $\left.8^{\text {th }} \mathrm{T} 2-\mathrm{T} 3 \mathrm{~N} 1\right)$, and RPA-III $\left(8^{\text {th }}\right.$ T2-T3N2). The RPA-IA, RPA-IB, RPA-IIA, RPA-IIB, and RPA-III stage groups included $226(4.0 \%), 646$ $(11.3 \%), 1310(22.9 \%), 2412(42.2 \%)$, and 1116 (19.5\%) of the patients in the training set, respectively. The corresponding median survival was $47,28,20,16$, and 14 months, respectively $(P<0.001$; Figure $3 \mathbf{A})$. A higher RPA stage was associated with an increased risk of death after adjusted for clinicopathologic factors (RPA-IB vs. RPA-IA: HR, 1.40; $P<0.01$; RPA-IIA vs. RPA-IA: HR, 2.04; $P<0.001$; RPA-IIB vs. RPA-IA: HR, 2.73; $P<0.001$; RPA-III vs. RPA-IA: HR, 3.30; $P<0.001)$. 
A

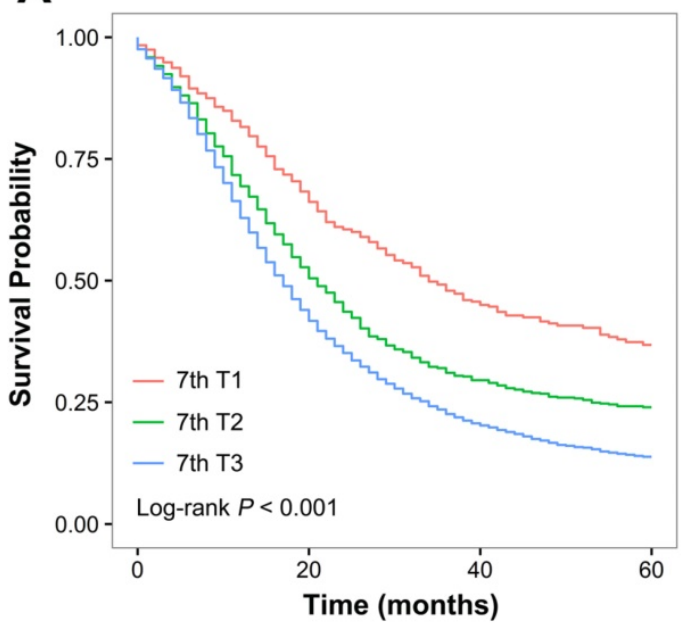

B

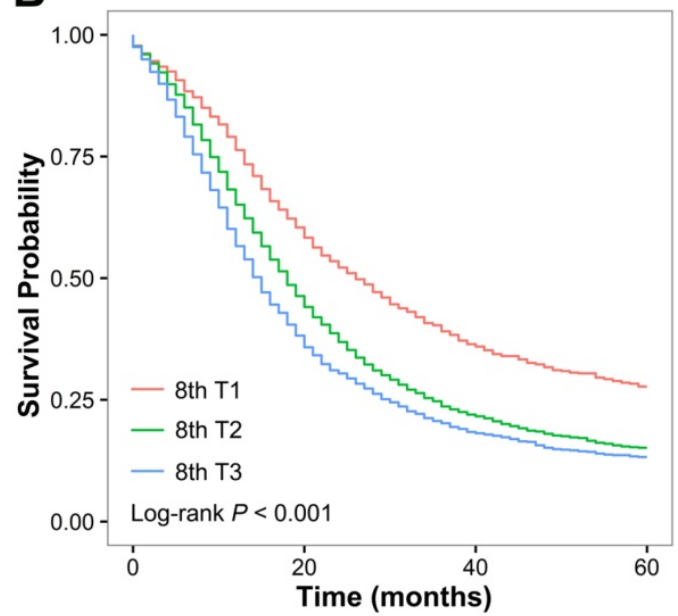

C



Figure 1. Overall survival for the study cohort comprising 8564 patients with resectable pancreatic ductal adenocarcinoma. (A) Overall survival of patients with node-negative disease stratified by the $7^{\text {th }}$ AJCC T classification system. (B) Overall survival of patients with node-negative disease stratified by the $8^{\text {th }}$ AJCC $T$ classification system. (C) Overall survival of patients with 7th T3N0 disease stratified by SEER region.
As shown in Figure 3B and 3C, each $7^{\text {th }}$ AJCC and $8^{\text {th }}$ AJCC stage represented a distinct prognosis in the training set. Using RPA staging, patients with each $8^{\text {th }}$ AJCC stage of disease and $7^{\text {th }}$ stage IIA and IIB disease could be further stratified into subgroups with remarkably different OS rates; in contrast, OS was homogeneous when the patients with each RPA stage of disease were re-stratified by the $7^{\text {th }}$ or $8^{\text {th }}$ AJCC systems (Table 4). Of note, patients with $8^{\text {th }}$ stage IA disease (median survival: 36 months) could be further stratified into RPA-IIA and RPA-IA subgroups depending on the presence or absence of extrapancreatic extension, and a 21-month difference in median survival was found between patients classified as having RPA-IA and those classified as having RPA-IIA disease (47 vs. 26 months, $P<0.01$ ). Additionally, patients with $8^{\text {th }}$ T3N0 tumors extending beyond the pancreas and $8^{\text {th }} \mathrm{T} 2-\mathrm{T} 3 \mathrm{~N} 1$ tumors, who were classified into $8^{\text {th }}$ stage IIA and IIB groups, respectively, actually had similar survival (median survival: 16 months for both; $P=0.43$ ) and were both re-classified into RPA-IIB according to the RPA staging system. The findings in stratified analyses were consistent when applied to the validation set (Table 5).

Table 6 lists the parameters used to measure the discriminatory ability and prognostic homogeneity of the RPA staging and the $7^{\text {th }}$ and $8^{\text {th }}$ AJCC staging schemes. For both the training and validation sets, the RPA staging system showed significantly greater discriminatory power than the $7^{\text {th }}$ and $8^{\text {th }}$ AJCC staging systems (training set: C-indices, 0.574 vs. $0.559 ; P<0.001$; validation set: $C$-indices, 0.575 vs. $0.558 ; P<0.01)$ and the $8^{\text {th }}$ AJCC staging system (training set: $C$-indices, 0.574 vs. $0.564 ; P=0.03$; validation set: $C$-indices, 0.575 vs. $0.562 ; P=0.04)$. The RPA staging scheme also outperformed the $7^{\text {th }}$ and $8^{\text {th }}$ AJCC staging schemes in terms of the AIC and the likelihood ratio $\chi^{2}$ value in both the training and validation sets.

\section{Discussion}

The recently proposed $8^{\text {th }}$ AJCC staging scheme [5] has notable modifications in the $\mathrm{T}$ and $\mathrm{N}$ classifications compared to the $7^{\text {th }}$ staging scheme. Tumor size was the only factor considered to determine the $8^{\text {th }} \mathrm{T}$ classification for resectable PDAC regardless of the involvement of peripancreatic soft tissue, whereas node-positive disease was further classified into N1 (1-3 positive nodes) and N2 classification ( $\geq 4$ positive nodes) in the $8^{\text {th }}$ staging.

In the present study of patients with resectable PDAC from the SEER database, we first compared the performance of the $7^{\text {th }}$ and $8^{\text {th }}$ AJCC T classifications using stratified survival analyses. For patients with 
N0 disease, both the $7^{\text {th }}$ and $8^{\text {th }}$ AJCC T classification systems showed significant heterogeneity in survival when assessed against each other, suggesting that there is scope to improve both these schemes. Therefore, we performed RPA to develop a new staging scheme for resectable PDAC that incorporated the $7^{\text {th }}$ and $8^{\text {th }} \mathrm{T}$ classifications along with the $8^{\text {th }} \mathrm{N}$ classifications.

RPA is a kind of nonparametric multivariable analysis that can repeatedly dichotomize the study population into smaller and smaller subsets [7]. The process of binary stratification is repeated based on covariates that maximize the change in an index of diversity, which accounts for prior probabilities and penalties for misclassification [11, 12]. Additionally, RPA is able to identify synergistic interactions among covariates [11]. Moreover, Kattan et al. reported that the RPA-based model exhibited a superior predictive accuracy to the traditional Cox proportional hazards regression model [13].
RPA has been widely used in other malignancies [14-17]. One of the most common applications and advantages is that it is able to objectively and intuitively generate several risk-groups for a desired endpoint. For instance, Huang et al. performed RPA to regroup the current AJCC $\mathrm{T}$ and $\mathrm{N}$ classifications and proposed a RPA staging system for human papilloma virus (HPV)-related cancer [16]. Compared with the current AJCC staging for oropharyngeal cancer, the RPA staging significantly improved survival prediction for patients with HPV-related oropharyngeal cancer, without increasing complexity [16]. Another common application and advantage of RPA is that it is capable of identifying optimal cutoff values for continuous covariates of interests. For instance, by using RPA among patients with chronic lymphocytic leukemia, Cui et al. defined a threshold for ROR1 surface expression that could categorize the cohort into ROR1-High vs. ROR1-Low subgroups with significantly different survival outcomes [15].

Table 2. Comparison of prognostic homogeneity between the $7^{\text {th }}$ and $8^{\text {th }}$ AJCC T classification schemes

\begin{tabular}{|c|c|c|c|c|c|c|c|}
\hline \multirow[t]{2}{*}{ Staging scheme } & \multicolumn{2}{|c|}{ 7th $\mathrm{T} 1$} & \multicolumn{2}{|c|}{ 7th $\mathrm{T} 2$} & \multicolumn{2}{|c|}{ 7th T3 } & \multirow[t]{2}{*}{$P$ value* } \\
\hline & No. & Median survival & No. & Median survival & No. & Median survival & \\
\hline \multicolumn{8}{|l|}{$8^{\text {th }} \mathrm{T}$ stage } \\
\hline $8^{\text {th }} \mathrm{T} 1$ & 226 & 47 months & - & - & 236 & 26 months & $<0.01$ \\
\hline $8^{\text {th }} \mathrm{T} 2$ & - & - & 298 & 32 months & 821 & 20 months & $<0.001$ \\
\hline $8^{\text {th }} \mathrm{T} 3$ & - & - & 112 & 21 months & 308 & 16 months & $<0.01$ \\
\hline$P$ value $\S$ & & - & & 0.08 & & $<0.01$ & \\
\hline
\end{tabular}

AJCC, American Joint Committee on Cancer; RPA, recursive partition analysis

${ }^{*}$ Comparison of OS within different 7 th $\mathrm{T}$ classifications. Bold $P$ values indicate statistical significance (i.e., $P<0.05$ ).

$\S$ Comparison of OS within different 8 th T classifications. Bold $P$ values indicate statistical significance (i.e., $P<0.05$ ).

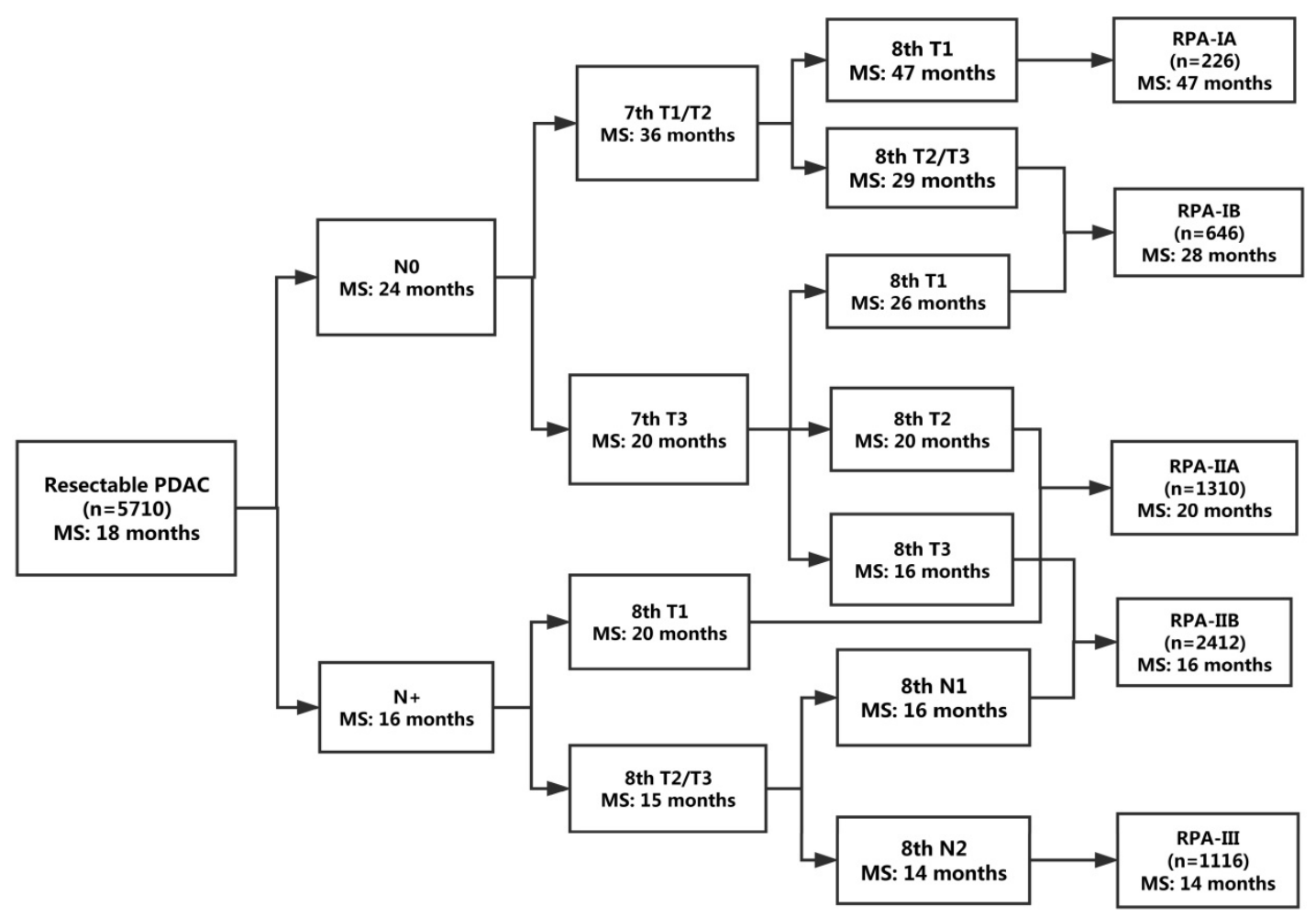

Figure 2. Refined stage grouping for resectable PDAC on the basis of RPA. MS, median survival. 
A

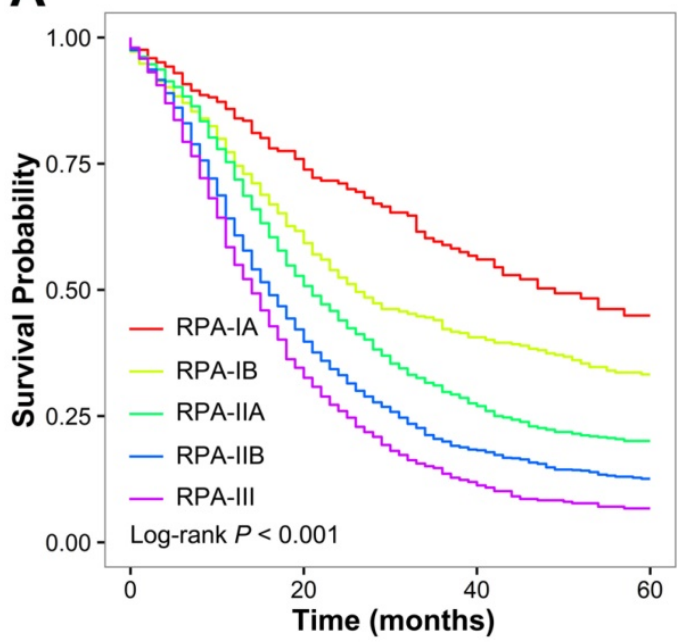

B
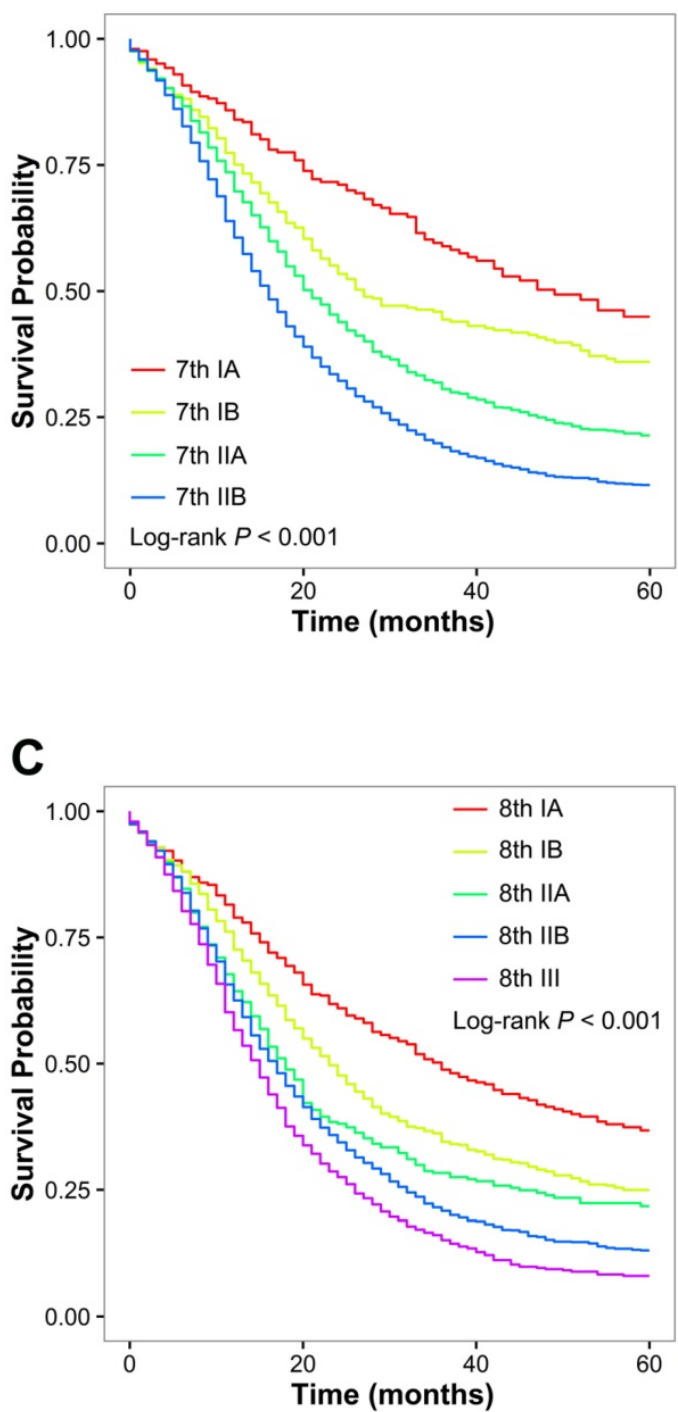

Figure 3. Overall survival of patients with resectable pancreatic ductal adenocarcinoma from the training set. (A) Overall survival of patients stratified by RPA stage. (B) Overall survival of patients stratified by the 7 th AJCC stage. (C) Overall survival of the patients stratified by the 8 th AJCC stage.
Table 3. Characteristics of patients in the training and validation sets

\begin{tabular}{|c|c|c|}
\hline \multirow[t]{2}{*}{ Variable } & \multirow{2}{*}{$\begin{array}{l}\text { Training set } \\
(\mathrm{N}=5710) \\
\text { Median (IQR)/N (\%) }\end{array}$} & \multirow{2}{*}{$\begin{array}{l}\text { Validation set } \\
(\mathrm{N}=2832) \\
\text { Median (IQR)/N (\%) }\end{array}$} \\
\hline & & \\
\hline Age, years & $66(58-74)$ & $66(58-74)$ \\
\hline \multicolumn{3}{|l|}{ Race } \\
\hline White & $4688(82.1)$ & $2326(82.1)$ \\
\hline Black & $602(10.5)$ & $294(10.4)$ \\
\hline Other & $420(7.3)$ & $212(7.5)$ \\
\hline \multicolumn{3}{|l|}{ Sex } \\
\hline Male & $2876(50.4)$ & $1456(51.4)$ \\
\hline Female & $3227(62.0)$ & $1376(48.6)$ \\
\hline \multicolumn{3}{|l|}{ Marital status } \\
\hline Married & 3554 (62.2) & $1764(62.3)$ \\
\hline Unmarried & $2002(35.1)$ & $990(35.0)$ \\
\hline Unknown & $154(2.7)$ & $78(2.8)$ \\
\hline \multicolumn{3}{|l|}{ Year of diagnosis } \\
\hline 2004-2006 & $1612(28.2)$ & $825(29.1)$ \\
\hline 2007-2009 & 1989 (34.8) & $977(34.5)$ \\
\hline 2010-2012 & 2109 (36.9) & $1030(36.4)$ \\
\hline \multicolumn{3}{|l|}{ SEER region } \\
\hline Midwest & $901(15.8)$ & 451 (15.9) \\
\hline Northeast & 1110 (19.4) & $501(17.7)$ \\
\hline South & 1009 (17.7) & $477(16.8)$ \\
\hline West & $2690(47.1)$ & $1403(49.5)$ \\
\hline \multicolumn{3}{|l|}{ Tumor site } \\
\hline Head & 4427 (77.5) & $2214(78.2)$ \\
\hline Body & $322(5.6)$ & $156(5.6)$ \\
\hline Tail & $426(7.5)$ & $222(7.8)$ \\
\hline Not specified & $535(9.4)$ & $237(8.4)$ \\
\hline \multicolumn{3}{|l|}{ Tumor grade } \\
\hline $\mathrm{I} / \mathrm{II}$ & 3277 (57.4) & $1586(56.0)$ \\
\hline III/IV & $1884(33.0)$ & $972(34.4)$ \\
\hline Unknown & $549(9.6)$ & $274(9.7)$ \\
\hline Tumor size & $31(25-40)$ & $31(25-40)$ \\
\hline$\leq 2 \mathrm{~cm}\left(8^{\text {th }} \mathrm{T} 1\right)$ & $951(16.7)$ & $515(18.2)$ \\
\hline$>2 \mathrm{~cm}$ and $\leq 4 \mathrm{~cm}\left(8^{\text {th }} \mathrm{T} 2\right)$ & $3366(58.9)$ & 1697 (59.9) \\
\hline$>4 \mathrm{~cm}\left(8^{\text {th }} \mathrm{T} 3\right)$ & $1393(24.4)$ & $620(21.9)$ \\
\hline \multicolumn{3}{|l|}{ 7th AJCC T stage } \\
\hline $\mathrm{T} 1$ & $339(5.9)$ & $211(7.5)$ \\
\hline $\mathrm{T} 2$ & 833 (14.6) & $383(13.5)$ \\
\hline $\mathrm{T} 3$ & 4538 (79.5) & $2238(79.0)$ \\
\hline Positive node count & $1(0-3)$ & $1(0-3)$ \\
\hline $0\left(8^{\text {th }} \mathrm{N} 0\right)$ & $2001(35.0)$ & $1048(37.0)$ \\
\hline $1-3\left(8^{\text {th }} \mathrm{N} 1\right)$ & $1967(34.4)$ & $902(31.9)$ \\
\hline$\geq 4$ (8th $\mathrm{N} 2)$ & $1742(30.5)$ & $882(31.1)$ \\
\hline Examined node count & $13(7-19)$ & $12(7-19)$ \\
\hline
\end{tabular}

For the training set, the RPA staging scheme outperformed the $7^{\text {th }}$ and $8^{\text {th }}$ AJCC staging schemes in terms of discriminatory power and in stratified survival analyses. Even though the RPA staging was only slightly better in terms of discrimination, it was considerably superior to the $7^{\text {th }}$ and $8^{\text {th }}$ AJCC schemes in stratified survival analyses. With the additional ability to distinguish survival between patients with PDAC of diameter $\leq 4 \mathrm{~cm}$ and those with PDAC of diameter $>4 \mathrm{~cm}$, the RPA staging scheme was able to further stratify patients within the $7^{\text {th }}$ stage IIA and IIB group into different risk groups. Additionally, it is noteworthy that each $8^{\text {th }}$ AJCC stage group could be 
classified by the RPA system into subgroups with remarkably different OS rates. For example, the $8^{\text {th }}$ stage IA disease ( $\left.8^{\text {th }} \mathrm{T} 1 \mathrm{~N} 0\right)$ was further stratified into RPA-IIA and RPA-IA disease depending on the presence or absence of extrapancreatic extension, and the difference in median survival between patients in these two groups exceeded 20 months. In contrast, OS was homogeneous within each RPA stage regardless of the $7^{\text {th }}$ and $8^{\text {th }}$ AJCC staging. For example, $8^{\text {th }}$ T3N0 tumors extending beyond the pancreas and $8^{\text {th }}$ T2-T3N1 tumors, which were classified into different prognostic subgroups on the basis of the $8^{\text {th }}$ AJCC staging ( $8^{\text {th }}$ stage IIA and IIB, respectively), actually had similar survival and were both classified into RPA-IIB. The results of the likelihood ratio $\chi^{2}$ tests also support the findings from stratified survival analyses.
Moreover, the predictive superiority of the RPA staging scheme was further verified using the validation set, which indicates minimal evidence of model overfit and the potential generalizability of the RPA staging scheme.

Currently, adjuvant chemotherapy followed by curative surgery is a standard treatment for PDAC $[18,19]$. However, the OS benefits of adjuvant chemotherapy are modest (difference in median OS: $<5$ months) in view of the results of the CONKO-001[20] and ESPAC-1 trials [21]. In this context, the RPA staging scheme will be clinically useful for treatment planning for the decision-making regarding adjuvant chemotherapy, which may help improve survival in selected patients and avoid overtreatment in others.

Table 4. Comparison of prognostic homogeneity between the $7^{\text {th }}$ and $8^{\text {th }}$ AJCC schemes and the RPA staging scheme for the training set

\begin{tabular}{|c|c|c|c|c|c|c|c|c|c|c|c|}
\hline \multirow[t]{2}{*}{ Staging scheme } & \multicolumn{2}{|c|}{ RPA-IA } & \multicolumn{2}{|c|}{ RPA-IB } & \multicolumn{2}{|c|}{ RPA-IIA } & \multicolumn{2}{|c|}{ RPA-IIB } & \multicolumn{2}{|c|}{ RPA-III } & \multirow[t]{2}{*}{$P$ value } \\
\hline & No. & $\begin{array}{l}\text { Median } \\
\text { survival }\end{array}$ & No. & Median survival & No. & Median survival & No. & Median survival & No. & $\begin{array}{l}\text { Median } \\
\text { survival }\end{array}$ & \\
\hline \multicolumn{12}{|l|}{$7^{\text {th }}$ AJCC stage } \\
\hline IA & 226 & 47 months & - & - & - & - & - & - & - & - & - \\
\hline IB & - & - & 410 & 29 months & - & - & - & - & - & - & - \\
\hline IIA & - & - & 236 & 26 months & 821 & 20 months & 308 & 16 months & - & - & $<0.001$ \\
\hline IIB & - & - & - & - & 489 & 20 months & 2104 & 16 months & 1116 & 14 months & $<0.001$ \\
\hline$P$ value ${ }^{b}$ & - & - & & 0.37 & & 0.96 & & 0.47 & & - & \\
\hline \multicolumn{12}{|l|}{$8^{\text {th }}$ AJCC stage } \\
\hline IA & 226 & 47 months & 236 & 26 months & - & - & - & - & - & - & $<0.01$ \\
\hline IB & - & - & 298 & 32 months & 821 & 20 months & - & - & - & - & $<0.001$ \\
\hline IIA & - & - & 112 & 21 months & - & - & 308 & 16 months & - & - & $<0.01$ \\
\hline IIB & - & - & - & - & 367 & 22 months & 2104 & 16 months & - & - & $<0.001$ \\
\hline III & - & - & - & - & 122 & 18 months & - & - & 1116 & 14 months & $<0.01$ \\
\hline$P$ value & & - & & 0.15 & & 0.62 & & 0.43 & & - & \\
\hline
\end{tabular}

AJCC, American Joint Committee on Cancer; RPA, recursive partition analysis

aComparison of overall survival within different RPA stages. Bold $P$ values indicate statistical significance (i.e., $P<0.05)$.

bComparison of overall survival within different $7^{\text {th }}$ AJCC stages. Bold $P$ values indicate statistical significance (i.e., $\left.P<0.05\right)$.

c Comparison of overall survival within different $8^{\text {th }}$ AJCC stages. Bold $P$ values indicate statistical significance (i.e., $P<0.05$ ).

Table 5. Comparison of prognostic homogeneity between the $7^{\text {th }}$ and $8^{\text {th }}$ AJCC schemes and the RPA staging scheme for the validation set

\begin{tabular}{|c|c|c|c|c|c|c|c|c|c|c|c|}
\hline \multirow[t]{2}{*}{ Staging scheme } & \multicolumn{2}{|c|}{ RPA-IA } & \multicolumn{2}{|c|}{ RPA-IB } & \multicolumn{2}{|c|}{ RPA-IIA } & \multicolumn{2}{|c|}{ RPA-IIB } & \multicolumn{2}{|c|}{ RPA-III } & \multirow[t]{2}{*}{ P value } \\
\hline & No. & Median survival & No. & Median survival & No. & Median survival & No. & Median survival & No. & Median survival & \\
\hline \multicolumn{12}{|l|}{ 7th AJCC stage } \\
\hline IA & 143 & 43 months $^{\mathrm{d}}$ & - & - & - & - & - & - & - & - & - \\
\hline IB & - & - & 198 & 24 months & - & - & - & - & - & - & - \\
\hline IIA & - & - & 116 & 24 months & 431 & 22 months & 160 & 16 months & - & - & 0.03 \\
\hline IIB & - & - & - & - & 256 & 21 months & 977 & 16 months & 551 & 15 months & $<0.001$ \\
\hline P value ${ }^{b}$ & - & - & & 0.72 & & 0.49 & & 0.22 & & - & \\
\hline \multicolumn{12}{|l|}{ 8th AJCC stage } \\
\hline IA & 143 & 43 months ${ }^{d}$ & 116 & 24 months & - & - & - & - & - & - & $<0.001$ \\
\hline IB & - & - & 156 & 24 months & 431 & 22 months & - & - & - & - & $<0.05$ \\
\hline IIA & - & - & 42 & 19 months & - & - & 160 & 16 months & - & - & 0.11 \\
\hline IIB & - & - & - & - & 210 & 21 months & 977 & 16 months & - & - & $<0.01$ \\
\hline III & - & - & - & - & 46 & 21 months & - & - & 551 & 15 months & 0.01 \\
\hline P value & & - & & 0.84 & & 0.77 & & 0.22 & & - & \\
\hline
\end{tabular}

AJCC, American Joint Committee on Cancer; RPA, recursive partition analysis

aComparison of overall survival within different RPA stages. Bold $P$ values indicate statistical significance (i.e., $P<0.05$ ).

bComparison of overall survival within different $7^{\text {th }}$ AJCC stages. Bold $P$ values indicate statistical significance (i.e., $\left.P<0.05\right)$.

c Comparison of overall survival within different $8^{\text {th }}$ AJCC stages. Bold $P$ values indicate statistical significance (i.e., $P<0.05$ ).

dThe median survival was not reached, and hence the mean survival time was provided instead. 
Table 6. Comparison of the performance of the RPA staging system with the $7^{\text {th }}$ and $8^{\text {th }}$ AJCC staging systems

\begin{tabular}{llll}
\hline Model & C-index & AIC & Likelihood ratio $\chi^{2}$ \\
\hline For the training set & & & \\
RPA staging & 0.574 & 59244.19 & 325.83 \\
7th AJCC staging & 0.559 & 59314.69 & 253.33 \\
8th AJCC staging & 0.558 & 59322.20 & 247.84 \\
For the validation set & & & \\
RPA staging & 0.575 & 26755.91 & 174.34 \\
7th AJCC staging & 0.564 & 26780.06 & 148.18 \\
8th $^{\text {th }}$ & 0.562 & 26793.34 & 136.80 \\
\hline
\end{tabular}

RPA, recursive partitioning analysis; AJCC, American Joint Committee on Cancer C-index, concordance index; AIC, Akaike's Information Criterion.

Prognostic nomograms that combine various prognostic factors, such as the one created by the Memorial Sloan-Kettering Cancer Center, have been proposed to refine survival prediction among patients with PDAC [22]. However, nomograms have not been widely used by patients and clinicians, probably due to their cumbersome nature and inherent complexities. In contrast, the proposed RPA staging scheme is based on the objective regrouping of the existing $7^{\text {th }}$ and $8^{\text {th }}$ AJCC stages, which are simple and widely accepted. Thus, it is important to note that the proposed RPA staging not only has a favorable prognostic performance but also is a convenient tool for treatment-related decision-making.

Previous studies investigating the prognostic impact of extrapancreatic extension have shown inconsistent findings $[5,22-28]$. One possible explanation for this may be differences in the clinicopathologic characteristics of the included cases. Most studies that failed to detect a significant correlation between extrapancreatic extension and survival included patients with T4 disease [22, 23, 25, 28], which was regarded as unresectable, while all three studies that reported a negative correlation between extrapancreatic extension and survival excluded patients with $\mathrm{T} 4$ disease $[5,24,27]$. In the present study after excluding patients with $\mathrm{T} 4$ disease, we also identified prominent differences in survival between patients with and without tumor extending beyond the pancreas across all the $8^{\text {th }} \mathrm{T}$ classifications.

The reproducibility of detecting extrapancreatic extension is a challenge for pathologists, because of the histologic complexity of the pancreas, including its lack of encapsulation and its complicated invaginations into peripancreatic soft tissue [4]. Allen et al. [5] reported that patients from different institutions classified as having $7^{\text {th }}$ T3N0 disease showed varying survival rates. However, in the present study of patients from the SEER database, survival rates were uniform among patients with $7^{\text {th }}$ T3N0 disease across different SEER regions. Although further studies to investigate the reproducibility of pathologic evaluation of extrapancreatic extension are necessary, our finding does support the stability of the $7^{\text {th }}$ AJCC T3 classification for prognosis in the general population.

The present study has some limitations. First, the measurement of tumor size was partially dependent on the percentage of tumor mesenchyme and the experience of the pathologist and may not always be accurate. Additionally, several important patient-level data were not available in the SEER data. For instance, because information regarding adjuvant chemotherapy was not reported, we could not evaluate how the proposed RPA staging may influence patient selection for adjuvant chemotherapy. Finally, this study was US-centric and patient cohorts from other countries are required to validate the RPA staging scheme.

In summary, we demonstrated that the prognostic accuracy of both the $7^{\text {th }}$ and $8^{\text {th }}$ AJCC T classification schemes needed improvement. Thus, we used population-based data and RPA to develop and validate a refined staging scheme for patients with resectable PDAC. The RPA staging system outperformed the $7^{\text {th }}$ and $8^{\text {th }}$ AJCC classification systems but was not substantially more complex. We expect that this newly proposed staging system will aid in decision-making regarding treatment and surveillance, as well as risk stratification in future prospective trials for patients with resectable PDAC.

\section{Abbreviation}

PDAC: Pancreatic ductal adenocarcinoma; AJCC: American Joint Committee on Cancer; RPA: recursive partitioning analysis; SEER: Surveillance, Epidemiology, and End Results; OS: Overall survival; HR: hazard ratio; C-index: concordance index; AIC: Akaike's information criterion; HPV: human papilloma virus.

\section{Acknowledgements}

We thank the staff members of the National Cancer Institute and their colleagues across the United States and at Information Management Services, Inc., who have been involved with the Surveillance, Epidemiology, and End Results (SEER) Program.

\section{Ethical approval}

Because SEER is public-use data, this study was deemed exempt from institutional review board approval by Sun Yat-Sen University Cancer Center.

\section{Informed consent}

Because SEER is public-use data, informed consent was waived. 


\section{Competing Interests}

The authors have declared that no competing interest exists.

\section{References}

1. Torre LA, Bray F, Siegel RL, Ferlay J, Lortet-Tieulent J, Jemal A. Global cancer statistics, 2012. CA Cancer J Clin. 2015; 65: 87-108.

2. Kamisawa T, Wood LD, Itoi T, Takaori K. Pancreatic cancer. Lancet. 2016; 388: 73-85.

3. Edge SB, Compton CC. The American Joint Committee on Cancer: the 7th edition of the AJCC cancer staging manual and the future of TNM. Ann Surg Oncol. 2010; 17: 1471-4.

4. Adsay NV, Bagci P, Tajiri T, Oliva I, Ohike N, Balci S, et al. Pathologic staging of pancreatic, ampullary, biliary, and gallbladder cancers: pitfalls and practical limitations of the current AJCC/UICC TNM staging system and opportunities for improvement. Semin Diagn Pathol. 2012; 29: 127-41.

5. Allen PJ, Kuk D, Castillo CF, Basturk O, Wolfgang CL, Cameron JL, et al. Multi-institutional Validation Study of the American Joint Commission on Cancer (8th Edition) Changes for T and N Staging in Patients with Pancreatic Adenocarcinoma. Ann Surg. 2016.

6. Harrell FE, Jr., Lee KL, Mark DB. Multivariable prognostic models: issues in developing models, evaluating assumptions and adequacy, and measuring and reducing errors. Stat Med. 1996; 15: 361-87.

7. Therneau TM, Atkinson EJ. An Introduction to Recursive Partitioning Using the RPART Routine Technical Report 61. Rochester Mayo Foundation. 1997.

8. O'Sullivan B, Huang SH, Su J, Garden AS, Sturgis EM, Dahlstrom K, et al. Development and validation of a staging system for HPV-related oropharyngeal cancer by the International Collaboration on Oropharyngeal cancer Network for Staging (ICON-S): a multicentre cohort study. The Lancet Oncology. 2016; 17: 440-51.

9. Aho K, Derryberry D, Peterson T. Model selection for ecologists: the worldviews of AIC and BIC. Ecology. 2014; 95: 631.

10. Lei Q, Qin Y. A Modified Likelihood Ratio Test for Homogeneity in Normal Mixtures of Two Samples with an Unknown Variance. Chinese Journal of Applied Probability \& Statistics. 2009; 25: 86-94.

11. Cook EF, Goldman L. Empiric comparison of multivariate analytic techniques: advantages and disadvantages of recursive partitioning analysis. J Chronic Dis. 1984; 37: 721-31.

12. Light RJ, Margolin BH. An Analysis of Variance for Categorical Data. J Am Stat Assoc. 1971; 66: 534-44

13. Kattan MW, Hess KR, Beck JR. Experiments to determine whether recursive partitioning (CART) or an artificial neural network overcomes theoretical limitations of Cox proportional hazards regression. Comput Biomed Res. 1998; 31: 363-73.

14. Chang JS, Kim KH, Yoon HI, Hyung WJ, Rha SY, Kim HS, et al. Locoregional relapse after gastrectomy with D2 lymphadenectomy for gastric cancer. Br J Surg. 2017.

15. Cui B, Ghia EM, Chen L, Rassenti LZ, DeBoever C. High-level ROR1 associates with accelerated disease progression in chronic lymphocytic leukemia. Blood. 2016; 128: 2931-40.

16. Huang $\mathrm{SH}, \mathrm{Xu} \mathrm{W}$, Waldron J, Siu L, Shen X, Tong L, et al. Refining American Joint Committee on Cancer/Union for International Cancer Control TNM stage and prognostic groups for human papillomavirus-related oropharyngeal carcinomas. J Clin Oncol. 2015; 33: 836-45.

17. Zhao Y, Li G, Zheng D, Jia M, Dai W, Sun Y, et al. The prognostic value of lymph node ratio and log odds of positive lymph nodes in patients with lung adenocarcinoma. J Thorac Cardiovasc Surg. 2017; 153: 702-9.e1.

18. National Comprehensive Cancer Network (NCCN). NCCN clinical practice guidelines in oncology (NCCN guidelines): pancreatic cancer. Available from URL: http://www.nccn.org/professionals/physician_gls/f_guidelines_ nojava.asp

19. Ducreux M, Cuhna AS, Caramella C, Hollebecque A, Burtin P, Goere D, et al. Cancer of the pancreas: ESMO Clinical Practice Guidelines for diagnosis, treatment and follow-up. Ann Oncol. 2015; 26 Suppl 5: v56-68.

20. Oettle H, Neuhaus P, Hochhaus A, Hartmann JT, Gellert K, Ridwelski K, et al. Adjuvant chemotherapy with gemcitabine and long-term outcomes among patients with resected pancreatic cancer: the CONKO-001 randomized trial. JAMA. 2013; 310: 1473-81.

21. Neoptolemos JP, Stocken DD, Friess H, Bassi C, Dunn JA, Hickey H, et al. A randomized trial of chemoradiotherapy and chemotherapy after resection of pancreatic cancer. N Engl J Med. 2004; 350: 1200-10.

22. Brennan MF, Kattan MW, Klimstra D, Conlon K. Prognostic nomogram for patients undergoing resection for adenocarcinoma of the pancreas. Ann Surg. 2004; 240: 293-8.

23. Saka B, Balci S, Basturk O, Bagci P, Postlewait LM, Maithel S, et al. Pancreatic Ductal Adenocarcinoma is Spread to the Peripancreatic Soft Tissue in the Majority of Resected Cases, Rendering the AJCC T-Stage Protocol (7th Edition) Inapplicable and Insignificant: A Size-Based Staging System (pT1: $</=2$, pT2: $>2-</=4$, pT3: $>4 \mathrm{~cm}$ ) is More Valid and Clinically Relevant. Ann Surg Oncol. 2016; $23: 2010-8$
24. Park H, An S, Eo SH, Song KB, Park JH, Kim KP, et al. Survival effect of tumor size and extrapancreatic extension in surgically resected pancreatic cancer: proposal for improved T classification. Hum Pathol. 2014; 45: 2341-6.

25. Lim JE, Chien MW, Earle CC. Prognostic factors following curative resection for pancreatic adenocarcinoma: a population-based, linked database analysis of 396 patients. Ann Surg. 2003; 237: 74-85.

26. de Jong MC, Li F, Cameron JL, Wolfgang CL, Edil BH, Herman JM, et al. Re-evaluating the impact of tumor size on survival following pancreaticoduodenectomy for pancreatic adenocarcinoma. J Surg Oncol. 2011; 103: 656-62.

27. Jamieson NB, Foulis AK, Oien KA, Dickson EJ, Imrie CW, Carter R, et al. Peripancreatic fat invasion is an independent predictor of poor outcome following pancreaticoduodenectomy for pancreatic ductal adenocarcinoma. J Gastrointest Surg. 2011; 15: 512-24.

28. Takai S, Satoi S, Toyokawa H, Yanagimoto H, Sugimoto N, Tsuji K, et al. Clinicopathologic evaluation after resection for ductal adenocarcinoma of the pancreas: a retrospective, single-institution experience. Pancreas. 2003; 26: 243-9. 